\title{
Reelin sets the pace of neocortical neurogenesis
}

Jarmila Lakomá $^{1}$, Luis Garcia-Alonso ${ }^{1} \&$ Juan M. Luque ${ }^{1,2}$

1. Instituto de Neurociencias, Universidad Miguel Hernández Consejo Superior de Investigaciones Científicas, Campus de San Juan s/n, E-03550 San Juan de Alicante, Spain.

2. Current address: San Vicente 106, E-03560 El Campello, Spain.

Correspondence to: Juan M. Luque ${ }^{1, \underline{2}}$ (Email: luque@ umh.es).

Keywords: Reelin, radial glia, cortex development.

Running Title: Reelin signaling in neuronal progenitors 
Summary

Migration of neurons during cortical development is often assumed to rely on purely post-proliferative Reelin signaling. However, Notch signaling, long known to regulate neural precursor formation and maintenance, is required for the effects of Reelin on neuronal migration. Here we show that Reelin-gain-of-function causes a higher expression of Notch target genes in radial glia and accelerates the production of both neurons and intermediate progenitor cells. Converse alterations correlate with Reelin-loss-of-function, consistent with Reelin controlling Notch signaling during neurogenesis. Ectopic expression of Reelin in isolated clones of progenitors causes a severe reduction in neuronal differentiation. In mosaic cell cultures, Reelinprimed progenitor cells respond to wild type cells by further decreasing neuronal differentiation, consistent with an increased sensitivity to lateral inhibition. These results indicate that Reelin and Notch signaling cooperate to set the pace of neocortical neurogenesis, a prerequisite for proper neuronal migration and cortical layering. 


\section{Introduction}

During neocortical development the biological programs underlying the generation, fate, and migration of nervous cells are tightly connected, both temporally and spatially. Indeed, mechanisms underlying precursor cell proliferation adjust the timing of neuronal production for specific neocortical layers (reviewed by Caviness et al., 2009). Cortical development progresses through an early phase of lateral progenitor expansion, a middle neurogenic phase of radial expansion, and a final phase of gliogenesis. During the neurogenic phase, the neocortical primordium, including the ventricular zone (VZ) and the subventricular zone (SVZ), balances the maintenance of neural precursor cells against the production of excitatory projection neurons (Miyata et al. 2009) which do not function in their birth places but undergo extensive radial migrations (Rakic, 2007). Molecular links between neurogenesis and migration have begun to be unraveled (Ge et al., 2006; Nguyen et al., 2006). However, migration of newborn neurons is often assumed to rely on purely postproliferative events, such as the Reelin signaling cascade, to establish the distinctive 'inside out' (later-born neurons past their predecessors) neocortical lamination pattern.

The gene mutated in reeler mice (reelin) encodes a secretable glycoprotein that controls the laminar position of cortical neurons by an 
unknown mechanism. Reelin is synthesized and secreted by Cajal-Retzius cells in the marginal zone. The plasma membrane Apolipoprotein Receptor 2 (ApoER2) and the Very Low Density Lipoprotein Receptor (VLDLR) along with the cytoplasmic adaptor protein Disabled 1 (Dab1) are known to constitute the initial components of the Reelin signaling pathway. Hence mutant null mice for Reelin, Dab1, or both ApoER2 and VLDLR, show similar layering defects in the neocortex. It is well established that Reelin binding to ApoER2 and VLDLR induces Dab1 phosphorylation, a tyrosine kinase signal transduction cascade, and Dab1-regulated turnover (Rice and Curran, 2001; Tissir and Goffinet, 2003; Cooper, 2008). Although Reelin signaling decoding is often assumed to occur exclusively in neurons, neural progenitors located next to newborn neurons might receive a functional Reelin signal (Luque, 2007). To date, the bulk of the published analysis on the Reelin function has been limited to a loss-of-function approach. The reeler mice display no obvious problems with the proliferative mechanisms; and their lineage sequences, and the appropriate classes of neurons, seem to arise in the appropriate order. Cortical neurons also seem to retain their principal class characteristic features of size and pattern of afferent and efferent connections - despite a poor, rather 'outside in', pattern of lamination (Caviness et al., 2008). 
Notch signaling, long known to keep neural progenitor character inhibiting neuronal differentiation, has recently been shown to play a key role in mediating the effects of Reelin on neuronal migration (HashimotoTorii et al., 2008). The fact that Notch can directly bind Dab1 (Keilani and Sugaya, 2008; Hashimoto-Torii et al., 2008), as does the Drosophila homolog (Giniger 1998), lends support to the notion that Reelin and Notch pathways may functionally interact (Gaiano, 2008). While most previous studies have focused on the fact that Reelin signaling is active in neurons, there is evidence that cells in the VZ, where neural progenitors reside, can respond to exogenous Reelin by phosphorylating Dab1 (Magdaleno et al., 2002). An enrichment of functional Reelin receptors (i.e. those present in the plasma membrane as mature forms) in the VZ/SVZ interface with a concomitant downregulation of Reelin receptors in migrating projection neurons, also implies that primary Reelin action occurs at early/premigratory stages (Uchida et al. 2009). Reelin receptors and Notch are expressed in radial glia (Luque et al., 2003; Luque, 2007; Gaiano et al., 2000) and activation of both pathways promotes a radial glial character, including expression of the radial glial marker BLBP (Hartfuss et al., 2003; Gaiano et al., 2000). Moreover, a Reelin-dependent increase of Notch intracellular domain has been described in a human cortical progenitor cell line (Keilani and Sugaya, 2008). As neocortical radial glial cells give rise 
to most, if not all, projection neurons (Noctor et al., 2001; Miyata et al., 2001; Tamamaki et al., 2001) while they are believed to serve as their primary migratory scaffold (Rakic, 1972), perturbations in radial glia could result in aberrant neurogenesis and/or neuronal migration. Understanding the early function of Reelin is fundamental to interpret any later requirement based on a mutant phenotype, which may reflect altered neural determination and/or differentiation.

In the present study, we use both loss- and gain-of-function approaches to investigate the function of Reelin in neocortical neurogenesis. We seek to reveal whether earlier than in migrating neurons the Reelin and Notch pathways cooperate in the neural progenitor cells regulating their development. Our results show that Reelin is necessary and sufficient to modulate the rate of neurogenesis during neocortical development. They suggest that Reelin acting upstream of Notch signaling regulates the temporal specification of neural progenitors and neuronal differentiation.

\section{Materials and Methods}

\section{Mice}

Heterozygous reeler mice were purchased from Jackson Laboratory (Bar Harbor, ME). The nestin-reelin transgenic mice were the generous gift 
from S. Magdaleno and T. Curran (Magdaleno et al., 2002). The GFP mice were the generous gift of O. Marin (Hadjantonakis et al. 2002). The day of vaginal plug appearance was considered to be embryonic day 0 (E0). Animals were handled according to protocols approved by the European Union, NIH guidelines, and the Animal Care and Use Committee of the Instituto de Neurociencias.

\section{Genotyping}

Primers used for ne-reelin:

Nerl-fwd 5'-GAGCAGGGCAGGTGCTCATTTCC-3',

Nerl-rev 5'-GTTCAGGTCCTCCTCGGAATATC-3'),

MBC (Mouse Beta Casein)-fwd 5'-GATGTGCTCCAGGCTAAAGTT-3', MBC-rev 5'-AGAAACGGAATGTTGTGGAGT-3'.

The transgene amplified a $1000 \mathrm{bp}$ band, and the MBC-control amplified a $500 \mathrm{bp}$ band. The PCR conditions were: $94^{\circ} \mathrm{C} 5 \mathrm{~min}, 35$ cycles of $94^{\circ} \mathrm{C} 1$ $\min , 57^{\circ} \mathrm{C} 1 \mathrm{~min}$ and $72^{\circ} \mathrm{C} 2 \mathrm{~min}$, final elongation at $72^{\circ} \mathrm{C} 10 \mathrm{~min}$.

Primers used for reelin:

GM75 5'-TAATCTGTCCTCACTCTGCC- 3',

3R1 5'-TGCATTAATGTGCAGTGTTG-3',

3W1 5'-ACAGTTGACATACCTTAATC-3'. 
The wildtype amplified a 242 bp band, the mutated allele amplified a 275 bp band. The PCR conditions were: $94^{\circ} \mathrm{C} 4 \mathrm{~min}, 30$ cycles of $94^{\circ} \mathrm{C} 1 \mathrm{~min}$, $55^{\circ} \mathrm{C} 2 \mathrm{~min}$ and $72^{\circ} \mathrm{C} 2 \mathrm{~min}$, final elongation at $72^{\circ} \mathrm{C} 10 \mathrm{~min}$.

Reverse transcriptase polymerase chain reaction (RT-PCR) and western blotting

Total RNA was isolated from $10 \times 10^{6}$ cells $/ \mathrm{ml}$ of un-differentiated neurospheres using TRIZOL (Sigma). cDNA was generated using a First Strand cDNA Synthesis Kit (Roche).

RT-PCR sequences:

GAPDH-fwd: 5'-TGATGACATCAAGAAGGTGGTGAAG-3', GAPD- rev: 5'-TCCTTGGAGGCCATGTAGGCCAT-3', REELIN-fwd: 5'-GAGGTGTATGCAGTG-3', REELIN-rev: 5'-TCTCACAGTGGATCC-3'.

GAPDH amplified a control band of 249 bp and Reelin a 591 bp band. The GAPDH PCR conditions were: $95^{\circ} \mathrm{C}$ for $5 \mathrm{~min}, 35$ cycles of $95^{\circ} \mathrm{C}$ for $30 \mathrm{sec}, 60^{\circ} \mathrm{C}$ for $30 \mathrm{sec}$ and $72^{\circ} \mathrm{C}$ for $1 \mathrm{~min}$, final elongation at $72^{\circ} \mathrm{C}$ for 5 min. The Reelin PCR conditions were: $95^{\circ} \mathrm{C}$ for $3 \mathrm{~min}, 30$ cycles of $95^{\circ} \mathrm{C}$ for $30 \mathrm{sec}, 55^{\circ} \mathrm{C}$ for $30 \mathrm{sec}$ and $72^{\circ} \mathrm{C}$ for $1 \mathrm{~min}$, final elongation $72^{\circ} \mathrm{C}$ for 5 min. Recombinant Reelin was produced and western blot analysis was performed as previously described (Sáez-Valero et al., 2003). 


\section{Neurosphere culture and mosaic assays}

NSCs were isolated from the dorsal forebrain of E14 mouse embryos. Cells were cultured in serum-free Neurobasal medium (Gibco) with B27 supplement (Gibco), EGF (Sigma) (20 ng/ml) and bFGF (Sigma) (10 $\mathrm{ng} / \mathrm{ml})$ mitogens, and heparin (Sigma) $(0.7 \mathrm{U} / \mathrm{ml})$, in non-coated plastic. Cells were passaged every four days by complete cluster disintegration into a single cell culture. For differentiation assays we used whole neurospheres after the first passage on pre-coated culture plastic dishes treated with Laminin (Sigma) $(0.5 \mathrm{mg} / \mathrm{ml})$ for five hours. Cells were cultured for periods of three and six days (DIV). Differentiation medium consisted of Neurobasal medium (Gibco) with $10 \%$ of FBS (Sigma), without EGF, bFGF and heparin. For mosaic assays we used NSCs from WT GFP mice and reeler ne-reelin transgenic mice after the first passage. Different fractional combinations of neurospheres, varying from 15 to $90 \%$, were seeded on pre-coated culture dishes and differentiated for four days before immunostaining.

\section{Cell-cycle exit and ventricular length analysis}

For cell-cycle exit analysis, the pregnant dam was injected with BrdU (100 $\mathrm{mg} / \mathrm{kg}$ ) on E13-E14. Reeler and ne-reelin embryos were compared to WT 
in two different set of experiments. Embryos were harvested $18 \mathrm{hr}$ following the injection and the brains processed for BrdU/Ki67 double immunolabeling. The fraction of cells that had exited the cell cycle was estimated by counting the number of BrdU+ cells and the number of BrdU+/Ki67- in a similar area. The cell-cycle exit fraction reported is the number of BrdU+/Ki67- cells divided by the total number of BrdU cells. Both the experimental procedure and the range of the control values in WT where similar to those previously published (Siegenthaler et al., 2009). Analysis of E14 dorsal forebrain length consisted of measuring the length of the ventricular surface from the pallial-subpallial boundary to the most dorsal point of the forebrain ventricular lumen in coronal sections from a similar rostral/caudal level.

\section{Immunohistochemistry}

Undifferentiated and differentiated NSCs were fixed with $4 \%$ paraformaldehyde (Sigma) in PBS for 20 min. After washing, cells were blocked for 1.5 hour in PBS plus $4 \%$ BSA (Sigma) and $0.5 \%$ of Triton $\mathrm{X} 100$ (Sigma). The cells were then incubated at $4^{\circ} \mathrm{C}$ overnight with the primary antibodies in blocking solution, washed, and incubated with secondary antibodies for two hours at room temperature. After washing, DAPI was applied for $10 \mathrm{~min}$ and cells were mounted in Flouromount 
(Sigma) media. Undifferentiated neurospheres were mounted onto glass slides with spacers and Fluoromount-G mounting media (Southern Biotech). For immunohistochemistry, embryos were either fixed by immersion or perfused transcardially with $4 \%$ paraformaldehyde (Sigma) in phosphate buffer (PB $0.01 \mathrm{M}, \mathrm{pH}$ 7.4). Brains were post-fixed during 48 hours in $4 \%$ paraformaldehyde followed by 24 hours in PB containing $20 \%$ sucrose (Sigma) for cryoprotection. Brains of different genotypes were arranged side by side and embedded together in the same block of gelatin matrix prior to cryosectioning at a thickness of 50 micrometres. This type of embedding enables us to perform the immunostaining using the same conditions for different brains. Floating sections were blocked for one hour in KPBS with $10 \%$ FBS and $0.025 \%$ Triton X100. They were then incubated with primary antibodies in KPBS with $1 \%$ serum and $0.025 \%$ Triton X100 overnight at room temperature. After washing, they were incubated with secondary antibodies in KPBS for two hours at room temperature. Conventional antigen retrieval and signal amplification procedures were applied prior to Notch intracellular domain (NICD) immunostaining. Finally, the sections were incubated with DAPI and mounted.

Primary antibodies: mouse anti-Reelin (G10, 1:500, from A. Goffinet), rabbit anti-Tuj1 (1:3000, Covance), rabbit anti-GFAP (1:750, 
Dako), rabbit anti-BLBP (1:1000, Chemicon), rabbit anti-Tbr2 (1:250, Abcam and from R. Hevner), mouse anti-H3P (1:200, Cell Signaling Technology), rabbit anti-Hes1 (1:250, Millipore), rabbit anti-Ctip2 (1:500, Abcam), rat anti-BrdU (1:250, Abcam), rabbit anti-Ki67 (1:50, Abcam), rabbit anti-cleaved-Caspase 3 (1:50, Cell Signaling Technology), rabbit anti-cleaved NICD (1:50, Abcam). Secondary antibodies: Cy2-donkey antirabbit, Cy2-donkey anti-mouse, Cy3-donkey anti-rabbit, Cy3-donkey antimouse, Cy5-donkey anti-mouse (1:200, all from Jackson Immunoresearch). 4', 6-diaminobenzidino-2-phenylindole, dilactate (DAPI) (300 nM, Invitrogen) was used for counterstaining.

\section{Data acquisition and statistical analysis}

Images were captured on a Leica TCS SP2 AOBS inverted laser scanning confocal microscope or a NIKON fluorescent microscope equipped with a confocal structured light system (Optigrid). Volocity 5.2, Image J (NIH, http://rsb.info.nih.gov/ij/) and Adobe Photoshop software were used for image capture and analysis. GFAP- and beta-Tubulin-III positive cells were counted in at least 10 randomly chosen fields of the culture plates. GraphPad Prism software was used to perform an un-paired Student $t$ test for statistical significance. The values represent means \pm standard errors. 


\section{Results}

To investigate the function of Reelin in neocortical neurogenesis we took advantage of the classic reeler mice, deficient in Reelin (loss-of-function, LOF), and the ne-reelin transgenic mice (Magdaleno et al., 2002) that express Reelin under the control of a nestin promoter, which controls gene expression in neural precursor cells (NPCs) located in the ventricular zone during corticogenesis (Lothian and Lendahl, 1997). Thus, ne-reelin embryos bear ectopic expression of the Reelin protein in NPCs in the ventricular zone and constitute gain of function (GOF) conditions. In the presence of the endogenous Reelin protein, ectopic Reelin did not seem able to alter cell migration in the neocortex. However, in the reeler background, ectopic Reelin induced tyrosine phosphorylation of Dab1 in the ventricular zone and partially rescued neuronal positioning - and so giving rise to early pre-plate splitting (Magdaleno et al., 2002).

\section{Reelin regulates the production of neuronal progenitors and the rate of}

\section{neurogenesis}

To assess the density of cells in the M-phase of the cell cycle during the cortical neurogenic phase we examined immunofluorescent labeling of phosphoHistone-3 (PH3). PH3 labels both the primary proliferative 
population in the VZ, at the edge of the ventricular lumen (neuroepithelial/radial glial cells), and the secondary proliferative population in the SVZ at abventricular locations (intermediate progenitor cells, IPCs). IPCs are produced by the primary progenitors, radial glial cells (Kriegstein et al., 2006). When compared with wild type (WT) by embryonic day (E) 14, Reelin GOF cortex showed an increased density of PH3 positive (PH3+) cells in VZ and SVZ. Reelin LOF cortex showed a decreased VZ and SVZ proliferation when compared to the WT cortex. This phenotype was similar in the reeler ne-reelin animal (Fig. 1A, 1B) and so suggesting that the GOF phenotype results from the summatory effect of both ectopic and endogenous Reelin. Though comparable to older WT cortices, the density of PH3+ cells decayed abruptly by E15 in Reelin GOF cortices (Fig. S1A, S1B). At E14 the Reelin GOF dorsal forebrain was somewhat larger than those of WT and Reelin LOF. The comparable WT and Reelin LOF dorsal forebrain lengths (not shown) contrast with their mitotic index and this suggests a predominance of symmetric divisions in Reelin LOF conditions at some earlier developmental time. We looked at this indirectly by analyzing the ratio between the number of $\mathrm{PH} 3+$ cells and the length of the dorsal forebrain. The lower ratio in Reelin LOF when compared with WT and Reelin GOF conditions might be consistent with increased lateral expansion of the neuroepithelium. In 
contrast, the hint of a putative higher ratio in Reelin GOF when compared with WT cortices, would suggest a shortening of the neuroepithelium (Fig. 1C). We then measured the output of asymmetric divisions, neurons, and IPCs. A BromodeoxyUridine (BrdU)/Ki67 $18 \mathrm{~h}$ cell-cycle exit assay was used to examine neuron generation. BrdU-positive (BrdU+) but Ki67negative (Ki67-) cells were counted as cells that had exited the cell cycle during the $18 \mathrm{~h}$ interval. In the WT cortex, a band of BrdU+/Ki67- cells was apparent above the SVZ. When compared with WT, the number of this type of cells was somewhat lower in reeler (Fig. 2A, 2B), but higher in nereelin cortices (Fig. 2C, 2D). This observation suggests a larger and smaller proportion of proliferative divisions respectively (a higher percentage of NPCs remain proliferative in the former after the 18 hour period, while a lower percentage remain proliferative in the later), before quitting the cell cycle. Therefore, while a more exhaustive analysis of the proliferation dynamics will be required to demonstrate that the duration of the NPC cell cycle is modulated by Reelin, it seems clear that the neurogenic output in the $18 \mathrm{~h}$ period of the BrdU "pulse" comes under dynamic control of Reelin expression. Tbr2 immunostaining was used to examine the IPC population. Dramatic increases in Tbr2 expression were observed in the E14 Reelin GOF telencephalon, including the SVZ, the IZ and, interestingly, the lower part of the CP. Conversely, a significant 
decrease was observed in Reelin LOF telencephalon at the same gestational age (Fig. 3A) and this was modestly ameliorated by ectopic expression of Reelin (not shown). This observation is consistent with accelerated depletion of IPCs. However, abrupt decreases of Tbr2 expression were observed by E15 in Reelin GOF cortices (Fig. S2). To determine the consequences of the increased production of neurons and IPCs in Reelin GOF conditions, we examined the expression of Tbr1, a marker of preplate derivatives and layer VI postmitotic neurons (Bulfone et al., 1995). Significant increases in Tbr1 expression were observed in the E14 Reelin GOF cortex when compared with the WT cortex. Consistently, significant decreases in expression levels were observed in the Reelin LOF cortex (Fig. 3A. B), and barely rescued by ectopic expression of Reelin (not shown). An abrupt decrease in Tbr1 expression was also observed by E15 in Reelin GOF cortices, comparable to Tbr1 expression levels in older, E16-17, WT cortices (Fig. S2). We also examined the expression of the transcriptional modulator Ctip2 (Arlotta et al., 2005) and found that at E14 layer V neurons were more abundant in Reelin GOF cortices than in WT cortices (Fig. 3C). We estimated that this number is doubled in the Reelin GOF condition compared to WT based on the number of cells displaying a signal above the $50 \%$ threshold of fluorescence. Thus, Reelin GOF in the ventricular zone correlates with an early increase in both neuron and IPC 
production, which would be consistent with an earlier shortening of the cortical neuroepithelium. Opposite phenotypes appear with Reelin LOF, some of which tend to normalize with the ectopic expression of Reelin. The lack of a stronger effect of the ne-reelin transgene on rescuing these reeler defects in cortex is not surprising, since the low amount of transgenederived protein (ca. $20 \%$ or less than endogenous Reelin expression) [Magdaleno et al., 2002] corresponds to much less than a simple duplication of the gene. We conclude that Reelin regulates the early production of neuronal progenitors and neurons.

\section{Reelin enhances the expression of Notch target genes in radial glia}

The decrease in neuron output and IPC production in the Reelin LOF cortices may be caused by defects in forebrain patterning of the radial glia cell population. Radial glia cells arise early in development from the neuropithelial cells lining the ventricles, around the time that neurons also start to appear. All neuronal populations in the mouse brain are derived from radial glial cells expressing Brain Lipid Binding Protein [BLBP] (Anthony et al., 2004), a direct target of Notch signaling in radial glia (Anthony et al., 2005). We have previously shown a reduced expression of BLBP in the radial glia of Reelin LOF cortices (Hartfuss et al., 2003). We 
further evaluated BLBP expression during Reelin GOF and LOF cortical development together with that of Hes1, a classic Notch signaling sentinel target gene (Jarriault et al., 1995). Dramatic increases in both BLBP and Hes1 expression were observed in E14 Reelin GOF when compared with WT cortices. Conversely, significant decreases were observed in Reelin LOF cortices of the same gestational age, which were rescued by ectopic expression of Reelin (Fig. 4A). To confirm that the LOF and GOF conditions of Reelin affect Notch signaling itself, we evaluated the amount of cleaved-Notch intracellular domain (NICD). A significant increase in the NICD signal was found in ne-reelin VZ when compared with the WT VZ at E14 (Fig. 4B). Nevertheless, possibly due to limitations in the sensibility of the technique, we were unable to show a significant difference between reeler and WT (not shown). Consistent with premature maturation of the radial glial cell progenitor population and subsequent early increases in both neuron and IPC production, by E15 abrupt decreases of both BLBP and Hes1 were observed in Reelin GOF cortices (Fig. S3). We infer that radial glia responds to Reelin signaling with enhanced Notch signaling activation, including direct targeting of Hes1 and BLBP. 


\section{Expression of Reelin in individual clones of neural precursor cells}

(NPCs) causes a severe imbalance in the number of differentiating

\section{neurons}

Reelin binding to the surface of neuroepithelial and radial glial cells (Luque et al., 2003; Luque, 2007) might induce the enhanced expression of Notch target genes and drive radial glia maturation, including morphological changes (Hartfuss et al., 2003; Keilani and Sugaya, 2008; present results). This would cause a shift from the proliferative symmetric division phase (lateral expansion) to the neurogenic asymmetric division phase (radial expansion) that will result in the generation of neurons. In addition, Reelin may be acting via Notch upon the lateral inhibition mechanism in neurogenic radial glial cells. Either or both of these alternatives in turn strongly predict a differential behavior between isochronically isolated neural progenitors expressing Reelin versus those devoid of the protein upon differentiation. We tested this prediction using the neurosphere assay (Rietze and Reynolds, 2006) to derive individual clones of neural stem cells isolated from E14 cortices. Firstly, we confirmed the presence of Reelin signaling partners, including ApoER2 and Dab1, in undifferentiated WT neurospheres (Fig. S4A), consistent with the reported expression of both proteins in WT cortical radial glia (Luque et al., 2003; Luque, 2007). We were unable to detect significant expression of Reelin in WT 
undifferentiated neurospheres (not shown). We then decided to use more sensitive techniques such as RT-PCR (mRNA) and immunoblotting (protein). For comparative purposes recombinant Reelin was produced as previously described (D’Arcangelo et al., 1997). Extremely low levels of both Reelin mRNA (Fig. 5A) and protein (Fig. S4B) were detected in undifferentiated WT neurosphere lysates, consistent with the reported absence of Reelin in cortical radial glial cells (Schiffmann et al., 1997). In contrast, as neural stem cells are highly enriched in Nestin-expressing precursor cells, the undifferentiated neurospheres derived from E14 Reelin GOF transgenic cortices strongly express Reelin, irrespective of the endogenous reelin genetic background (Fig. 5A, S4B, S4C). We found that the expression of Reelin in undifferentiated neurospheres did not result in any significant morphological change in neurophere size (Fig. 5B), proliferation rate, or cell death (as assayed with PH3 and cleaved Caspase3, respectively) when compared with WT-derived neurospheres (Fig. 5C). This finding suggests that under non-differentiating conditions, expression of Reelin has no significant effect on in vitro progenitor growth. However, for neural stem cell differentiation, we observed a reduction in neuronal production (as assayed by Tuj1 expression) from differentiating neurospheres derived from E14 heterozygous and null mutant reelin cortices when compared with those derived from WT cortices. Remarkably, 
a much more dramatic reduction in neuron numbers was observed from transgenic ne-reelin differentiating neurospheres, irrespective of their endogenous reelin genetic background. Astroglial numbers in turn (as assayed by GFAP expression) showed a reciprocal trend in all assayed genotypes (Fig. 5D, 5E).

\section{Reelin expression sensitizes NPCs to lateral inhibition}

Notch signaling is pivotal for lateral inhibition, contributing to binary cell fate specification from an initially equipotent population (Heitzler and Simpson, 1991). During lateral inhibition, Notch signals cell autonomously after bind to its ligand (e.g. Delta) to maintain a non-neuronal fate (progenitor, epithelial, or glial) in cells neighboring a neural-committed cell (which expresses Delta). Lateral inhibition mediated by Delta-Notch signaling has been recently shown to govern neocortical neurogenesis, segregating equipotent neural precursor cells (NPCs) into two alternative fates: NPCs and neurons (Kawaguchi et al., 2008). To further analyze the function of Reelin in neurogenesis and whether Reelin acts on NPCs to favor lateral inhibition we designed a mosaic neurosphere assay. We mixed WT neurospheres derived from green fluorescent protein (GFP) mice and reeler ne-reelin (non-GFP) neurospheres in compositions ranging from $15 \%$ to $90 \%$ of ne-reelin NPCs, and induced simultaneous differentiation. 
Remarkably, the number of differentiated WT-GFP versus ne-reelin neurons did not correspond to that expected for mosaic composition. While no significant changes were observed in the number of neurons differentiated from WT NPCs, reeler ne-reelin NPCs differentiated far fewer neurons than expected based on their behavior in homogeneous culture conditions (Fig. 6A-C). Therefore, ne-reelin reeler NPCs are especially sensitive to the presence of WT cells with a higher proneural capacity. This reflects either or both, a sensitization to lateral inhibition by neural commited WT NPCs, or a sensitization to Reelin produced by some WT differentiating neurons. To distinguish between these alternatives, we stained the differentiating mosaic compositions for Reelin expression. We found a similar very low proportion of WT Reelin-expressing neurons in all mosaic compositions (not shown), suggesting that the enhanced sensitivity of ne-reelin reeler NPCs in avoiding neuronal differentiation relates to a higher susceptibility for lateral inhibition signals. These results strongly suggest that Reelin-primed NPCs have an enhanced Notch function that prevents them from entering the neuronal differentiation pathway. Likewise, no changes were observed in the number of astrocytes differentiated from WT NPCs. However, at high concentrations (75-90\%) of WT NPCs (those with a higher number of neurons and more faithfully mimicking the shift from neurogenesis to gliogenesis at later 
developmental stages) reeler ne-reelin NPCs significantly differentiate more astrocytes than expected - based on their behavior in homogeneous culture conditions (Fig. 6B, 6C). Together, these results strongly support the notion that Reelin modulates lateral inhibitory signals between NPCs, possibly by enhancing Notch function in NPCs, and so contributing to the determination of cell fate in the developing neocortex.

\section{Discussion}

The present study shows that the widely known physiological function of Reelin in neurons, i.e. the regulation of neuronal migration and positioning in the developing neocortex, is posterior to an earlier requirement for NPC maturation, cell cycle progression and control. Mechanistically, neocortical NPCs respond to Reelin expression with enhanced Notch activation, as revealed by the subsidiary expression of Hes1 and BLBP in radial glia and regulation of Tbr2 in IPCs. This, in turn, regulates both neuron and IPC production. Consistent with Reelin acting upstream of Notch signaling in NPCs, the expression of Reelin in isolated progenitors causes a severe reduction in the number of neurons that differentiate. Moreover, in mosaic cell cultures, the Reelin expressing progenitor cells respond to the higher pro-neuronal capacity of wild type cells by further decreasing neuronal 
differentiation, presumably because they are more sensitive to lateral inhibition than the WT progenitors. These results strongly suggest that Reelin enhances Notch signaling within progenitor cells.

The classical reeler mutant mouse "has contributed both insight and consternation' to the topic of proliferative vs. postproliferative determinants of cortical architectonic patterns (Caviness et al., 2008). Despite consistent anomaly in cell position, the attributes of cell class were found to be preserved in terms of the many aspects of cell appearance and the specificity of connections (Caviness and Rakic, 1978). Thus, the reeler provided the best evidence yet that the bulk of cell class specification is independent of the post migratory context with the implication that it is conferred prior to migration. A wide range of subsequent studies strengthens the conclusion that cortical neuron phenotype is specified before the onset of migration. Likewise, as the right cells were thought to be born at the right time but had failed to reach the right place in reeler, migration of newborn neurons was assumed to rely on purely postproliferative events to establish the distinctive 'inside out' neocortical lamination pattern. Recently though, it has been revealed that the identity of pyramidal neurons does not become immutable at the progenitor stage; but rather depends for final refinement on postmitotic expression of transcriptional modulators (Fishell and Hanashima, 2008). The present 
results indicate that cortical NPCs respond to reelin expression before postmitotic newborn neurons. Reelin GOF under a nestin driver expressed by NPCs correlates with an early increase in both neuron and IPC production. Reciprocal phenotypes correlate with Reelin LOF, and this is consistent with a previous observation (Polleaux et al., 1998) and indicates that changes in the rate of neuron production are attributable to changes in the proportion of neurogenic divisions. The fact that Reelin GOF does not produce an obvious migratory phenotype (Magdaleno et al., 2002) precludes the possibility of this effect being secondarily or fundamentally controlled by the postmigratory compartment. Importantly, because cells isolated from the cortical $\mathrm{VZ}$ are competent to respond to exogenous Reelin by Dab1 phosphorylation (Magdaleno et al., 2002), and indeed the Reelin receptor machinery, including Dab1, is expressed in cortical NPCs (Luque et al., 2003), all modifications of events in the VZ/SVZ are most likely the consequence of Reelin signaling decoding in NPCs. Thus, the reciprocally modified proliferative behavior of the pool of NPCs in Reelin GOF and LOF conditions provides evidence for a direct Reelin influence on the neocortical primordium. Such influence may have been previously missed since neither Reelin LOF, nor Reelin GOF, produce gross changes in the final number of mature cortical neurons. This clearly indicates that the total number of cells and the final size of the neocortex are developmentally 
controlled by other factors in addition to Reelin. The question as to whether the final number of neurons and glia is reached before or after the normal timing in WT pertains to only one of the variables that the developmental control system computes to achieve its species-specific final parameters. Consistent with our observations, a single study demonstrated lower rates of differentiative divisions for corticospinal neurons in the early stages of corticogenesis in the reeler; followed by a rebound of increased rates of differentiative divisions in the final stages of corticogenesis (Polleaux et al., 1998). We found a comparable WT and Reelin LOF dorsal forebrain length at E14. This is in contrast to the lower mitotic index found in Reelin LOF cortices, and suggests a predominance of symmetric divisions or a delayed entry into the neurogenic phase (enlargement of the neuroepithelium) in Reelin LOF conditions early during cortical development. Accordingly, the low cell cycle quitting fraction (neurogenic output) observed in Reelin LOF conditions suggest that precursors may remain longer on proliferative divisions or have a longer cell cycle. Reciprocally, the higher cell cycle quitting fraction observed in E14 Reelin GOF conditions suggests that precursors generating neurons and IPCs may undergo either a relatively shorter period of proliferative divisions or a faster cell cycle before quitting the cell cycle. In any event, it seems clear 
that the regulation of neocortical neurogenesis comes under dynamic control of Reelin expression.

We have previously demonstrated a significant reduction in VZ cells with long radial processes in the cortex of reeler mutants. These defects were correlated with a decrease in the expression of BLBP. In vitro, Reelin addition increased both the BLBP expression and the process extension of cortical radial glia. Isolation of radial glia by fluorescent-activated cell sorting showed that these effects were due to the direct action of Reelin on the radial glia cells. We could further demonstrate that this signaling requires Dab1, since the increase of BLBP upon Reelin additionally failed to occur in Dab1 null mutant mice (Hartfuss et al., 2003). Here we show that the radial glia reply to Reelin expression with Notch activation. While Reelin GOF increases the amount of cleaved-NICD, Reelin LOF decreases Notch signaling (as revealed by the expression of both Hes1 and BLBP). Moreover, the ectopic expression of Reelin in the reeler background rescued the Hes1 and BLBP expression in radial glia. Consistent with this, a recent work in a human progenitor cell line showed that Reelin treatment led to elevated NICD levels and enhanced radial glial characteristics (Keilani and Sugaya, 2008). Moreover, in the postnatal hippocampus Reelin enhances Notch signaling contributing to the formation of the radial glial scaffold (Sibbe et al., 2009). Notch signaling which inhibits proneural 
basic helix-loop-helix transcription factors and hence neuronal differentiation also appears to advance initiation of the neurogenic phase (Miyata et al., 2010). The emergence of Delta-like 1, a Notch ligand responsible for the activation of Notch signaling in the developing neocortex (Kawaguchi et al., 2008) roughly coincides with the onset of neurogenesis (Hatakeyama et al., 2004), and the forced activation or inactivation of the Notch pathway respectively increased and decreased expression of radial glia markers such as RC2 and BLBP (Gaiano et al., 2000; Anthony et al., 2005), suggesting that Noch signaling contributes to the mechanics of the switch from lateral expansion (symmetric) to neurogenic (asymmetric) divisions. Moreover, molecules involved in or susceptible to cross-talk with Notch signaling, such as Neuregulin 1 (Schmid et al., 2003), Fibroblast Growth Factors (Yoon et al., 2004; Sahara et al., 2009), or Retinoic Acid (Siegenthaler et al., 2009), have been recently identified as central in this transition. The expression of Reelin, secreted by Cajal-Retzius cells in the marginal zone, also roughly coincides with the onset of neurogenesis in the cortical plate. The close proximity to the radial glial endfeet enables a potent, short-range signal that does not need to directly influence IPC proliferation events. A further possibility is that Reelin signaling on NPCs comes from the cerebrospinal fluid. We and others have detected the presence of Reelin in the CSF (Sáez-Valero et al., 
2003; Ignatova et al., 2004) which is known to play a key role during early development. In any event, Reelin may cooperate with Notch signaling to advance the transit from the lateral expansion phase to the neurogenic phase by regulating the biochemical maturation from neuropithelial progenitors to radial glia.

Our in vitro studies confirm that Reelin acts upstream of Notch signaling in its most classical function, i.e., to inhibit neuronal differentiation and maintain progenitor/glial fate. Indeed, the transgenic expression of Reelin in isolated progenitors causes a dramatic reduction in the number of neurons that differentiate. In vitro neurosphere culture constitutes a developmental snapshot that should reflect the diverse developmental history and degree of maturation by E14 of the isolated progenitor cells. Since neurosphere cultures select only NPCs to survive and the nestin promoter driving Reelin expression occurs in NPCs but not in differentiating neurons, these results suggest that Reelin expression affects NPCs before or during the neurogenesis process. Together with previously published results (Hartfuss et al., 2003; Anthony et al., 2005; Keilani and Sugaya, 2008; Gaiano, 2008) they are consistent with the notion of Reelin acting upstream of Notch signaling in NPCs to regulate cell fate before differentiation. Our results also emphasize the need for combined GOF and LOF approaches, as conflicting results have been 
obtained in two reports upon differentiation of reeler derived neurospheres (Kwon et al., 2009; Massalini et al., 2009). The recent proposal that Dab1 suppresses astroglial differentiation, albeit independently of Reelin (Kwon et al., 2009), is seemingly incompatible with previously published results showing how the lack of Reelin accelerates the transition of radial glial cells to astrocytes (Hunter-Schaedle, 1997). This late observation is consistent with the notion of Reelin regulating the temporal specification of NPCs. The Delta-Notch pathway contributes to the lateral signaling between NPCs that segregates equipotent mouse neocortical NPCs into two alternative fates: NPCs and neurons (Kawaguchi et al., 2008). In our mosaic cell cultures, the Reelin-expressing progenitor cells respond through a lateral inhibition mechanism to the higher proneural capacity of wild type cells by further decreasing their neuronal differentiation with a concomitant increase in astroglial differentiation. Taken together, these results strongly support a role for Reelin in enhancing Notch function during neocortical neurogenesis. The question arises as to why would be important to amplify Notch signaling. The slow or delayed neurogenesis during early neocortical development in reeler may reflect the fact that that the promotion of progenitor proliferation is not robust enough. An amplifier of the Notch-Delta signaling such as Reelin that could add proliferative-promoting capacity to low Delta signals (so improving the 
robustness of progenitor proliferation) would certainly be an advantage in a system that has to grow exponentially. Thus, Reelin may enhance neurogenesis in the same way as an upward compression of the Notch signaling dynamic range in NPCs. The schematic drawing of Fig. 7 summarizes our results and proposal.

It has been recently proposed that neuronal migration in the developing cortex requires a Reelin-Notch interaction (Hashimoto-Torii et al., 2008). Loss of Notch signaling in newborn neurons resulted in migratory and morphological defects. Further, overexpression of Notch intracellular domain was found to mitigate the laminar and morphological abnormalities of migrating neurons in reeler. However, since the tubulin alpha-1 promoter element Hashimoto-Torii et al. (2008) used for their molecular manipulations in vivo can drive expression in the germinal zone (Gal et al., 2006) it is difficult to entirely rule out that altered Notch and/or Reelin signaling in the progenitor pool might have contributed to the effects observed in neurons (Gaiano, 2008). Here, we have provided experimental evidence supporting that Reelin acts as an operational amplifier of Notch signaling in neocortical NPCs. At first, Reelin appears to advance the transit from the lateral expansion phase to the neurogenic phase by regulating the biochemical maturation from neuropithelial progenitors to radial glia progenitors. Reelin then enhances the precise 
timing of neurogenesis by promoting radial glial fate while inhibiting neuronal differentiation. We propose that Reelin regulates the temporal specification of NPCs and thus couples neocortical neurogenesis to neuronal migration, and probably also to astrogliogenesis. Further elucidation of the underlying molecular mechanism of Reelin-Notch signaling action should reveal novel concepts and patterns that provide a clear link between their seemingly distinct proliferative and postproliferative functions. In the meantime, it seems increasingly evident that molecules regulating NPC proliferation, neurogenesis, and neuronal fate also regulate neuronal migration.

\section{Acknowledgements}

We thank Drs. S. Magdaleno and T. Curran for ne-reelin mice; Dr. O. Marín for GFP-mice; Drs. A. Goffinet and R. Hevner for Reelin and Tbr2 antibodies; Dr. M. Giménez y Ribotta, Dr. A. Fairén, Dr. E. Soriano and G. Expósito for reactives and expert technical advice. JL holds a JAE/CSIC predoctoral fellowship. This work was supported in part by grants from the Generalitat Valenciana-Prometeo 2008-134 (LGA), the Spanish Ministry of Science and Innovation SAF2004-07685 (JML), and the Fundación Médica Mútua Madrileña (JML). 
References

Anthony, T. E., Klein, C., Fishell, G. and Heintz, N. (2004). Radial glia serve as neuronal progenitors in all regions of the central nervous system. Neuron 41, 881-890.

Anthony, T. E., Mason, H. A., Gridley, T., Fishell, G. and Heintz, N. (2005). Brain lipid-binding protein is a direct target of Notch signaling in radial glial cells. Genes Dev. 19, 1028-1033.

Arlotta, P., Molyneaux, B. J., Chen, J., Inoue, J., Kominami, R. and Macklis, J. D. (2005). Neuronal subtype-specific genes that control corticospinal motor neuron development in vivo. Neuron 45, 207-221.

Bulfone, A., Smiga, S. M., Shimamura, K., Peterson, A., Puelles, L. and Rubenstein, J. L. (1995). T-brain-1: a homolog of Brachyury whose expression defines molecularly distinct domains within the cerebral cortex. Neuron 15, 63-78.

Caviness, V. S. Jr., Bhide, P. G. and Nowakowski R. S. (2008). Histogenetic processes leading to the laminated neocortex: migration is only a part of the story. Dev. Neurosci. 30, 82-95. 
Caviness, V. S. Jr., Nowakowski, R. S. and Bhide P. G. (2009). Neocortical neurogenesis: morphogentic gradients and beyond. Trends Neurosci. 32, 443-450.

Caviness, V. S. and Rakic, P. (1978). Mechanisms of cortical development: a view from mutations in mice. Annu. Rev. Neurosci. 1, 297326.

Cooper, J. A. (2008). A mechanism for inside-out lamination in the neocortex. Trends Neurosci. 31, 113-119.

D'Arcangelo, G., Nakajima, K., Miyata, T., Ogawa, M., Mikoshiba, K. and Curran, T. (1997). Reelin is a secreted glycoprotein recognized by the CR-50 monoclonal antibody. J Neurosci. 17, 23-31.

Fishell, G. and Hanashima, C. (2008). Pyramidal neurons grow up and change their mind. Neuron 57, 333-338.

Gaiano, N. (2008). Strange bedfellows: Reelin and Notch signaling interact to regulate cell migration in the developing neocortex. Neuron $\mathbf{6 0}$, 189-191.

Gaiano, N., Nye, J. S. and Fishell, G. (2000). Radial glial identity is promoted by Notch1 signaling in the murine forebrain. Neuron 26, 395404. 
Gal, J. S., Morozov, Y. M., Ayoub, A. E., Chatterjee, M., Rakic, P. and Haydar, T. F. (2006). Molecular and morphological heterogeneity of neural precursors in the mouse neocortical proliferative zones. J. Neurosci. 26, 1045-1056.

Ge, W., He, F., Kim, K. J., Blanchi, B., Coskun, V., Nguyen, L., Wu, X., Zhao, J., Heng, J.I., Martinowich, K., Tao, J., Wu, H., Castro, D., Sobeih, M. M., Corfas, G., Gleeson, J. G., Greenberg, M. E., Guillemot, F. and Sun, Y. E. (2006). Coupling of cell migration with neurogenesis by proneural bHLH factors. Proc. Natl. Acad. Sci. USA 103, 1319-1324.

Giniger, E. (1998). A role for Abl in Notch signaling. Neuron 20, 667-681.

Hadjantonakis, A. K., Macmaster, S., Nagy, A. (2002). Embryonic stem cells and mice expressing different GFP variants for multiple non-invasive reporter usage within a single animal. BMC Biotechnol. 2, 11.

Hartfuss, E., Förster, E., Bock, H. H., Hack, M. A., Leprince, P., Luque, J. M., Herz, J., Frotscher, M. and Götz, M. (2003). Reelin signaling directly affects radial glia morphology and biochemical maturation. Development 130, 4597-4609.

Hashimoto-Torii, K., Torii, M., Sarkisian, M. R., Bartley, C. M., Shen, J., Radtke, F., Gridley, T., Sestan, N. and Rakic, P. (2008). Interaction 
between Reelin and Notch signaling regulates neuronal migration in the cerebral cortex. Neuron 60, 273-284.

Hatakeyama, J., Bessho, Y., Katoh, K., Ookawara, S., Fujioka, M., Guillemot, F.and Kageyama, R. (2004). Hes genes regulate size, shape, and histogenesis of the nervous system by control of the timing of neural stem cell differentiation. Development. 131, 5539-5550.

Heitzler, P. and Simpson, P. (1991). The choice of cell fate in the epidermis of Drosophila. Cell 64, 1083-1092.

Hunter-Schaedle, K. E. (1997). Radial glial cell development and transformation are disturbed in reeler forebrain. J. Neurobiol. 33, 459-472.

Ignatova, N., Sindic, C. J. and Goffinet, A. M. (2004). Characterization of the various forms of the Reelin protein in the cerebrospinal fluid of normal subjects and in neurological diseases. Neurobiol. Dis. 15, 326-330.

Jarriault, S., Broum C., Logeat, F., Schroeter, E. H., Kopan, R. and Israel, A. (1995). Signalling downstream of activated mammalian Notch. Nature 337, 355-358.

Kawaguchi, D., Yoshimatsu, T., Hozumi, K. and Gotoh, Y. (2008). Selection of differentiating cells by different levels of delta-like 1 among 
neural precursor cells in the developing mouse telencephalon. Development 135, 3849-3858.

Keilani, S. and Sugaya, K. (2008) Reelin induces a radial glial phenotype in human neural progenitor cells by activation of Notch-1. BMC Dev. Biol. 8, 69 .

Kriegstein, A., Noctor, S. and Martínez-Cerdeño, V. (2006). Patterns of neural stem and progenitor cell division may underlie evolutionary cortical expansion. Nat. Rev. Neurosci. 7, 883-890.

Kwon, I. S., Cho, S. K., Kim, M. J., Tsai, M. J., Mitsuda, N., Suh-Kim, H. and Lee, Y. D. (2009). Expression of Disabled 1 supresses astroglial differentiation in neural stem cells. Mol. Cell Neurosci. 40, 50-61.

Lothian, C. and Lendahl, U. (1997). An evolutionarily conserved region in the second intron of the human nestin gene directs gene expression to CNS progenitor cells and early neural crest cells. Eur. J. Neurosci. 9, 452462.

Luque, J. M. (2007). Puzzling out the reeler brainteaser: does reelin signal to unique neural lineages? Brain Res. 1140, 41-50.

Luque, J. M., Morante-Oria, J. and Fairén, A. (2003). Localization of ApoER2, VLDLR and Dab1 in radial glia: groundwork for a new model of 
reelin action during cortical development. Brain Res. Dev. Brain Res. 140, 195-203.

Magdaleno, S., Keshvara, L. and Curran, T. (2002). Rescue of ataxia and preplate splitting by ectopic expression of Reelin in reeler mice. Neuron 33, 573-586.

Massalini, S., Pellegatta, S., Pisati, F., Finocchiaro, G., Farace, M. G. and Ciafrè, S. A. (2009). Reelin affects chan-migration and differentiation of neural precursor cells. Mol. Cell Neurosci. 42, 341-349.

Miyata, T., Kawaguchi, A., Okano, H. and Ogawa, M. (2001). Asymmetric inheritance of radial glial fibers by cortical neurons. Neuron 31, 727-741.

Miyata, T., Kawaguchi, D., Kawaguchi, A. and Gotoh, Y. (2010). Mechanisms that regulate the number of neurons during mouse neocortical development. Curr. Opin. Neurobiol. 20, 22-28.

Nguyen, L., Besson, A., Heng, J. I., Schuurmans, C., Teboul, L., Parras, C., Philpott, A., Roberts, J. M. and Guillemot, F. (2006). p27kip1 independently promotes neuronal differentiation and migration in the cerebral cortex. Genes Dev. 20, 1511-1524. 
Noctor, S. C., Flint, A. C., Weissman, T. A., Dammerman, R. S. and Kriegstein, A. R. (2001). Neurons derived from radial glial cells establish radial units in neocortex. Nature 409, 714-720.

Rakic, P. (1972). Mode of cell migration to the superficial layers of fetal mokey neocortex. J. Comp. Neurol. 145, 61-83.

Rakic, P. (2007). The radial edifice of cortical architecture: from neuronal silhouettes to genetic engineering. Brain Res. Rev. 55, 204-219.

Rice, D. S. and Curran, T. (2001). Role of the reelin signaling pathway in central nervous system development. Ann. Rev. Neurosci. 24, 1005-1039.

Rietze, R. L. and Reynolds, B. A. (2006). Neural stem cells isolation and characterization. Methods in Enzymology 419, 3-23.

Sáez-Valero, J., Costell, M., Sjögren, M., Andreasen, N., Blennow, K. and Luque, J. M. (2003). Altered levels of cerebrospinal fluid reelin in frontotemporal dementia and Alzheimer's disease. J. Neurosci. Res. 72, 132-136.

Sahara, S. and O'Leary, D. D. (2009). Fgf10 regulates transition period of cortical stem cell differentiation to radial glia controlling generation of neurons and basal progenitors. Neuron 63, 48-62. 
Schiffmann, S. N., Bernier, B. and Goffinet, A. M. (1997). Reelin mRNA expression during mouse brain development. Eur. J. Neurosci. 9, 1055-1071.

Schmid, R. S., McGrath, B., Berechid, B. E., Boyles, B., Marchionni, M., Sestan, N. and Anton, E. S. (2003). Neuregulin 1-erbB2 signaling is required for the establishment of radial glia and their transformation into astrocytes in cerebral cortex. Proc. Natl. Acad. Sci. USA 100, 4251-4256.

Sibbe, M., Foster, E., Basak, O., Taylor, V. and Frotscher, M. (2009). Reelin and Notch1 cooperate in the development of the dentate gyrus. $J$. Neurosci. 29, 8578-8585.

Siegenthaler, J. A., Ashique, A. M., Zarbalis, K., Patterson. K. P., Hecht, J. H., Kane, M. A., Folias, A. E., Choe, Y., May, S. R., Kume, T., Napoli, J. L., Peterson, A. S. and Pleasure, S. J. (2009). Retinoic acid from the meninges regulates cortical neuron generation. Cell 139, 597-609.

Tamamaki, N., Nakamura, K., Okamoto, K. and Kaneko, T. (2001). Radial glia is a progenitor of neocortical neurons in the developing cerebral cortex. Neurosci. Res. 41, 51-60. 
Tissir, F. and Goffinet, A. M. (2003). Reelin and brain development. Nat. Rev. Neurosci. 4, 496-505.

Uchida, T., Baba, A., Pérez-Martínez, F. J., Hibi, T., Miyata, T., Luque, J. M., Nakajima, K. and Hattori, M. (2009). Downregulation of fuctional Reelin receptors in projection neurons implies that primary Reelin action occurs at early/pre-migratory stages. J. Neurosci. 29, 10653-10662.

Yoon, K., Nery, S., Rutlin, M. L., Radtke, F., Fishell, G. and Gaiano, N. (2004). Fibroblast growth factor receptor signaling promotes radial glial identity and interacts with Notch1 signaling in telencephalic progenitors. $J$. Neurosci. 24, 9497-9506.

\section{Author's contribution}

JL performed the research and contributed to project design and the writing of the manuscript. LGA supervised the research and contributed to project design and the writing of the manuscript. JML conceived the project, supervised the research and wrote the manuscript.

Statement about competing interest: None declared. 


\section{Figure Legends}

Figure 1. Reelin regulates the number of dividing cortical NPCs. A. E14 reeler cortex (LOF condition) shows a decreased number of $\mathrm{VZ}$ and SVZ mitosis (PH3 labeling). The E14 ne-reelin cortex (GOF condition) shows an increased density of mitosis in the VZ and the SVZ. In the reeler background the ne-reelin transgene does not rescue the mitotic index to WT levels. B. Quantification of the number of PH3+ cells in the cortical VZ. C. Ratio between the number of VZ PH3+ cells and the VZ length. Note that the lower ratio in reeler when compared with WT and ne-reelin cortices may be consistent with early increased lateral expansion of the neuroepithelium in Reelin LOF conditions. In contrast, the somewhat larger ratio in ne-reelin when compared with WT cortices, suggests a putative shortening of the neuroepithelium in Reelin GOF conditions. D. A schematic drawing showing the dorso-ventral and rostro-caudal level of the regions where the immunnofluoresce (box) and the length of ventricular surface (red line) are analyzed. VZ: ventricular zone; SVZ: subventricular zone; IZ: intermediate zone; CP: cortical plate. DAPI (counterstaining) Calibration bar: 50 micrometers. 


\section{Figure 2. The output of cortical neurogenic divisions relies on Reelin}

expression. In this cell-cycle exit assay by E13-14 a bromodeoxyuridine (BrdU) pulse was followed 18h later by Brdu/Ki67 immunostaining. BrdU positive but Ki67 negative cells were considered as cells that had exited the cell cycle. A. Representative staining from BrdU/Ki67 cell-cycle exit assay in WT vs. reeler cortex. When compared with WT, the number of cells that had exited the cell cycle was somewhat lower in reeler. B. Percent of BrdU+/Ki67- cells in WT vs. reeler cortices. C. Representative staining from BrDU/Ki67 cell-cycle assay in WT vs. ne-reelin cortex. When compared with WT, the number of cells that had exited the cell cycle was significantly higher in ne-reelin cortices. D. Percentage of BrdU+/Ki67- in WT vs. ne-reelin cortices. VZ: ventricular zone; SVZ: subventricular zone; IZ: intermediate zone; arrows indicate the putative migratory front of postmitotic neurons. Calibration bar: 50 micrometers.

\section{Figure 3. Reelin regulates the timed production of IPCs and projection}

neurons. A. The expression of the transcription factor Tbr2 reveals IPCs in the most basal part of the VZ, the SVZ, and the most apical part of the IZ. When compared with E14 WT, Tbr2 expression was reduced in reeler but dramatically increased in ne-reelin cortices. Note that even the lower part 
of the cortical plate expresses small amounts of Tbr2 in the ne-reelin cortex. The expression of the transcription factor Tbr1 reveals in turn layer VI cortical neurons and preplate derivatives. When compared with WT, Tbr1 expression was reduced in reeler but strongly increased in ne-reelin cortices. Note that even cells in the IZ express low levels of Tbr1 in the nereelin cortex. B. A quantitative analysis of the number of Tbr2+ and Tbr1+ cells. C. The expression of the transcriptional modulator Ctip2 reveals layer V cortical neurons. Based on their immunnofluorescence, layer V neurons were elearly ca. twice more abundant in ne-reelin cortices than in WT. VZ: ventricular zone; SVZ: subventricular zone; IZ: intermediate zone; CP: cortical plate. DAPI (counterstaining). Calibration bars: 50 micrometers.

Figure 4. Reelin enhances the expression of NICD and the Notch target genes BLBP and Hes1 in NPCs. A. Reduced expression of both BLBP and Hes1 are noticeable in reeler cortices by E14 when compared with WT. In contrast, a conspicuous increase of both BLBP and Hes1 appears in ne-reelin cortices. The ectopic expression of Reelin rescues the expression of these Notch-target genes in compound reeler ne-reelin cortices. B. The ne-reelin transgene enhances the expression of cleaved-Notch intracellular 
domain in the ventricular zone. IZ: intermediate zone; CP: cortical plate. Calibration bars: 50 micrometers (4A), 25 micrometers (4B).

Figure 5. The expression of Reelin in individual clones of NPCs strongly reduces neuronal differentiation. A. Extremely low levels of Reelin mRNA are detectable in lysates of undifferentiated neurospheres generated from E14 dorsal forebrain, consistent with the reported absence of Reelin in NPCs. In contrast, ne-reelin neurospheres, even those with an endogenous reeler background, strongly express Reelin. B. The expression of the ne-reelin transgene does not modify the size of undifferentiated neurospheres. C. Under non-differentiating conditions the expression of the ne-reelin transgene does not result in any significant change in proliferation rate or cell death, as assayed with PH3 and cleaved-Caspase 3, respectively. D. Representative fields depicting young neurons (Tuj1+) and astrocytes (GFAP+) in differentiating neurospheres. E. Quantification of neurons and astrocytes in differentiating neurospheres. When compared with WT neurospheres, a somewhat reduced neuronal production is observed in reeler neurospheres. A dramatic reduction in neuron numbers is observed in transgenic ne-reelin neurospheres, irrespective of their 
genetic background for endogenous Reelin. Astroglial numbers showed a reciprocal trend in all assayed genotypes.

Figure 6. Reelin acts on NPCs during lateral inhibition. A. Mosaic neurosphere differentiation assay. Representative fields depicting young neurons (Tuj1+) in a mix of WT neurospheres derived from green fluorescent protein (GFP) mice and reeler ne-reelin (non-GFP) mice in compositions ranging from $15 \%$ to $90 \%$ of ne-reelin NPCs. Top and bottom images show the same field in the $R G$ and $R B$ channels respectively B. Quantification of reeler ne-reelin neurons and astrocytes differentiated in mosaic conditions. Note that reeler ne-reelin NPCs differentiate far fewer neurons than those expected based on their behavior in homogeneous (non-mosaic) culture conditions. The strength of this inhibitory effect clearly correlates with the proportion of WT NPCs in the mosaic. This suggests that Reelin expression sensitizes NPCs to lateral inhibition. At high concentrations of WT NPCs (interestingly, those that more faithfully mimic the developmental shift from neurogenesis to gliogenesis), reeler ne-reelin NPCs differentiate more astrocytes than those expected based on their behavior in homogeneous cultures. $1, P=0.0010, n$ $=10 ; 2, P=0.0038, n=10 ; 3, P=0.0061, n=10 ; 4, P=0.0109, n=10 ; 5$, 
$P=0.0484, n=10 ; 6, P=0.0170, n=10$. C. Quantification of WT neurons and astrocytes differentiated in mosaic conditions. No significant changes are observed as WT NPCs differentiate the expected numbers of neurons and astrocytes based on their behavior in homogeneous culture conditions.

Figure 7. Proposed model. Reelin upstream of Notch regulates the temporal specification of NPCs and neuronal differentiation. During neocortical development, NPCs sequentially pass through phases of lateral expansion, radial expansion (neurogenesis), and gliogenesis. During the expansion phase, NPCs, referred to as neuroepithelial cells (NE), expand their population by symmetric cell divisions. However, around the onset of the neurogenic phase, NPCs mature into radial glia (RG) which simultaneously self-renew and generate neurons (N) either directly or indirectly via intermediate progenitor cells (IPC) through asymmetric cell divisions. A. Inferred dynamics of cortical neurogenesis in Reelin LOF and GOF conditions compared to WT. Reelin may cooperate first with Notch in the maturation of $\mathrm{NE}$ to $\mathrm{RG}$ and thus regulating the timed onset of the neurogenic phase. Reelin loss-of-function (LOF) may delay and Reelin gain-of-function (GOF) may advance the onset of neurogenesis. B. Reelin enhances the Notch function during neurogenesis. The emergence of Cajal- 
Retzius cells (CR) expressing and secreting Reelin roughly coincides with the onset of neurogenesis. Reelin via the Reelin receptor machinery (RR) expressed by RG cooperates with Notch, also expressed by RG, to regulate the expression of target genes such us BLBP and Hes1. This, in turn, contributes to the maintenance of the progenitor pool, and so setting directly and indirectly (via IPCs expressing Tbr2) the pace of neocortical neurogenesis. 


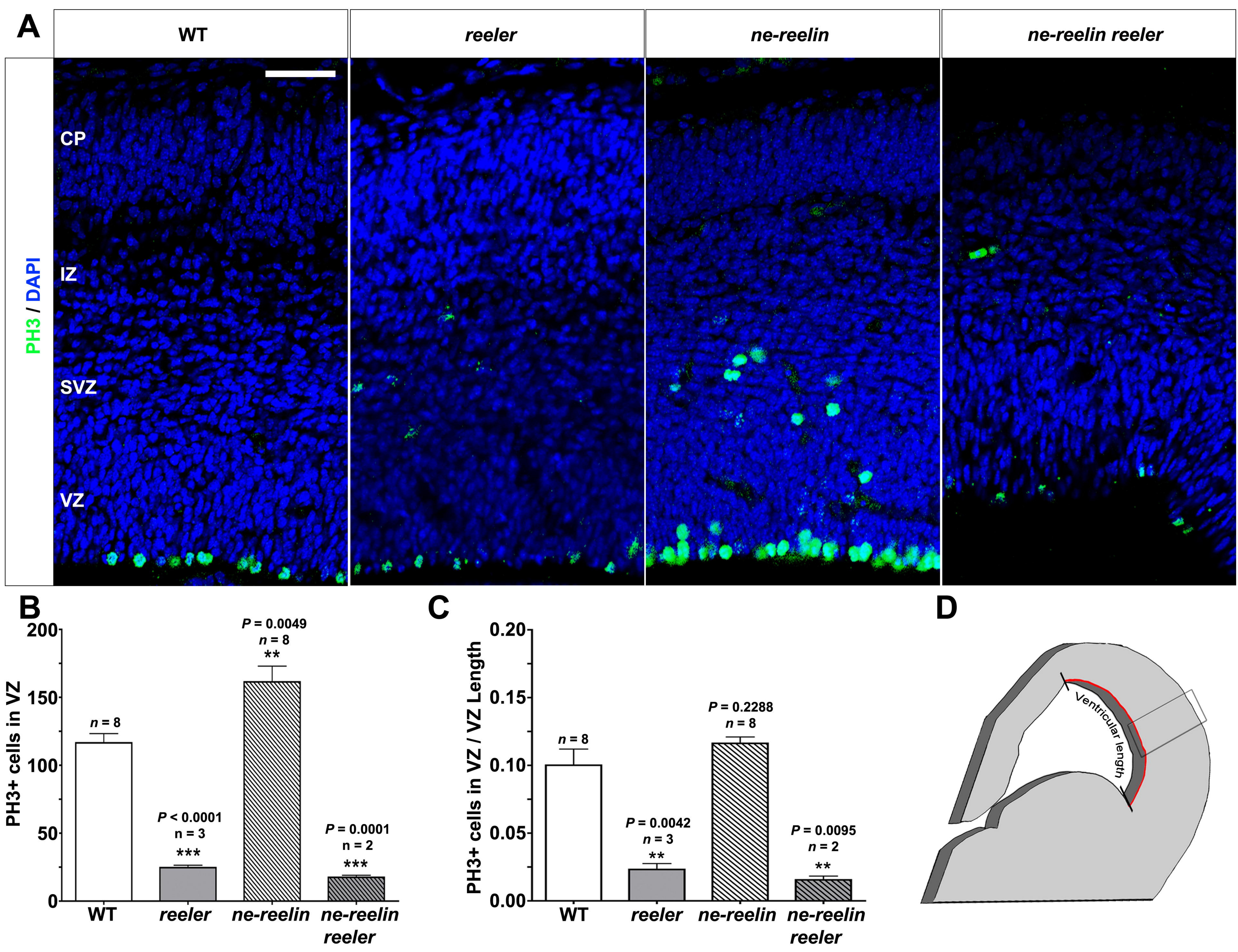

\section{FIGURE 1}




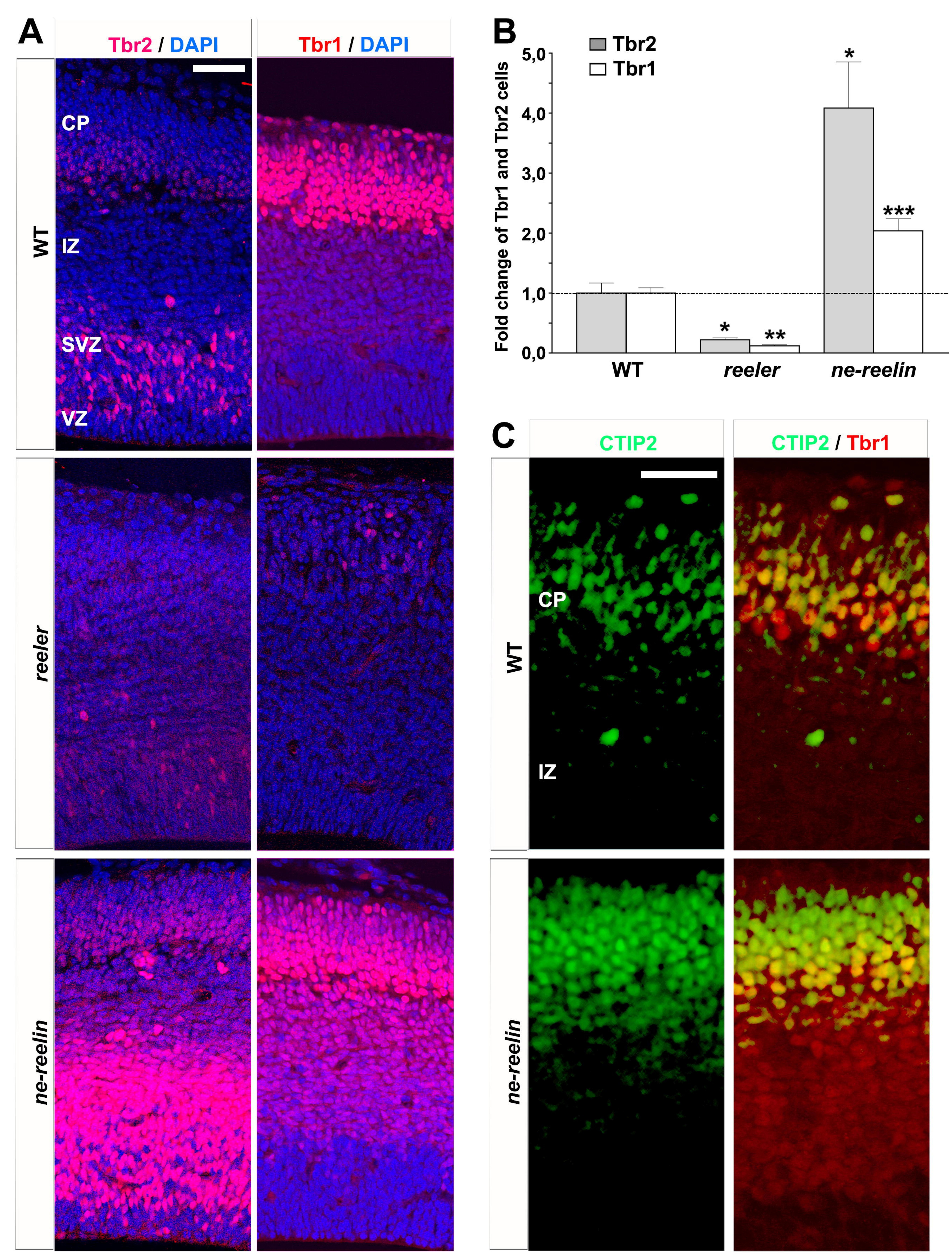

FIGURE 3 



FIGURE 5 

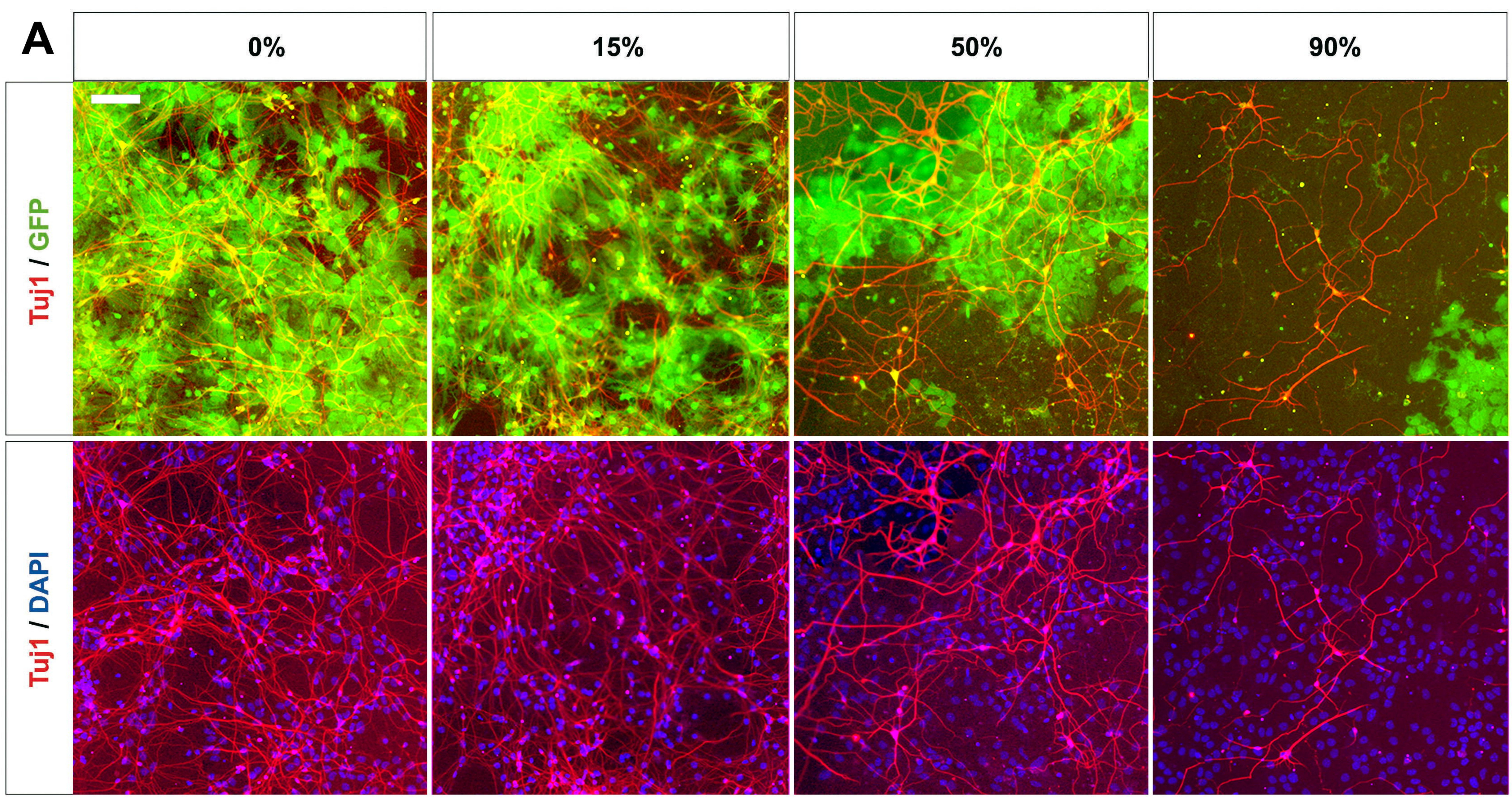

\section{B}

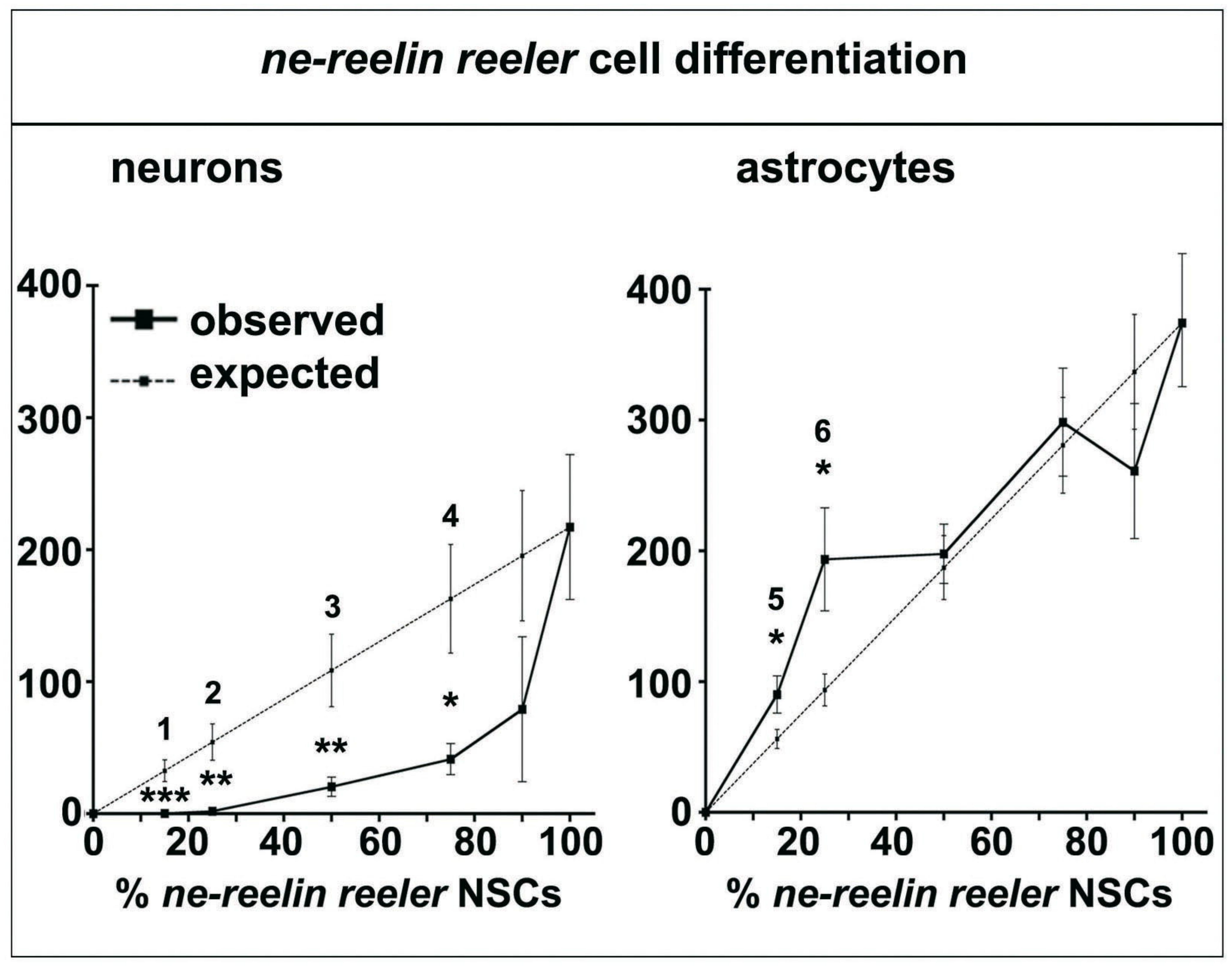

C

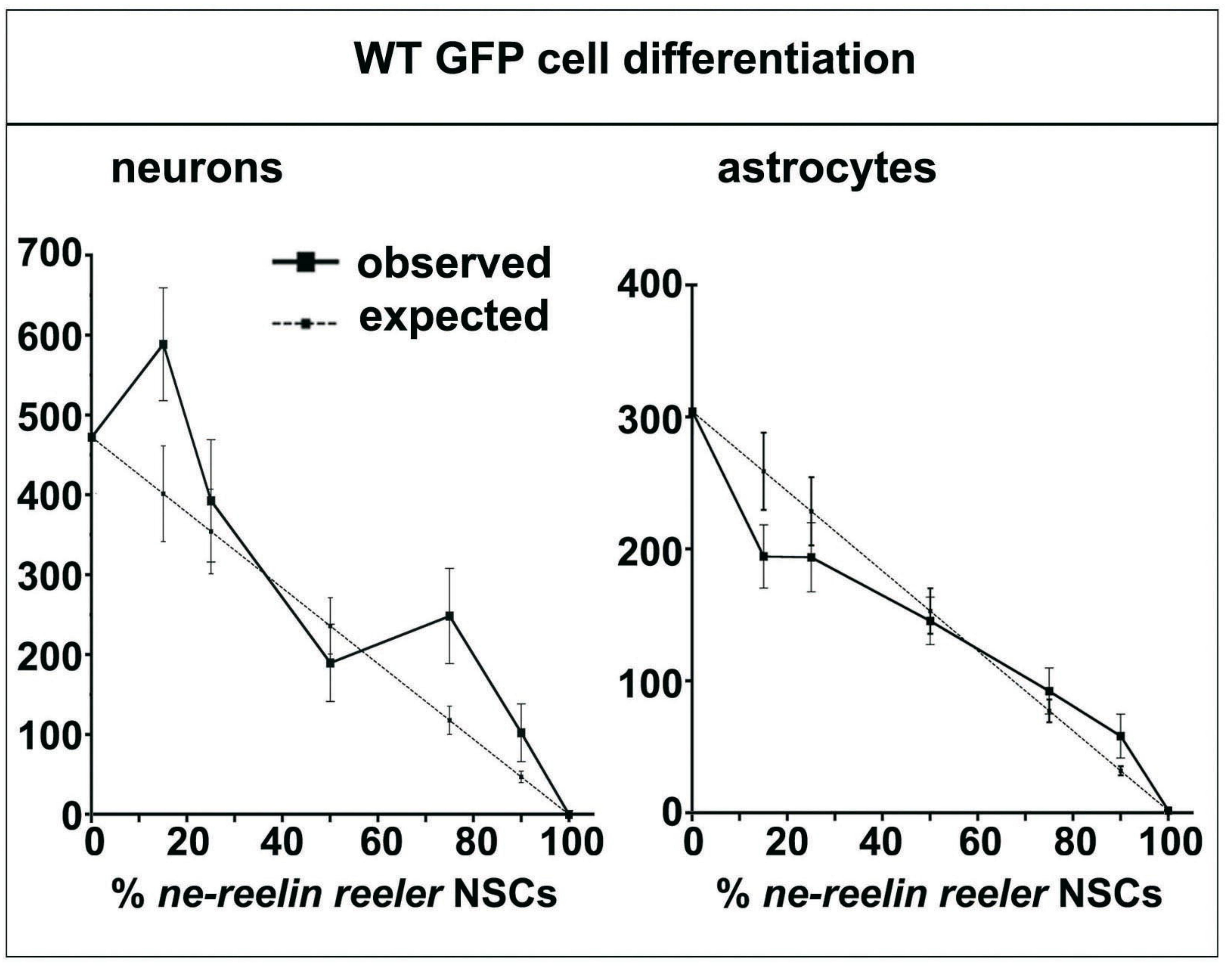

FIGURE 6 

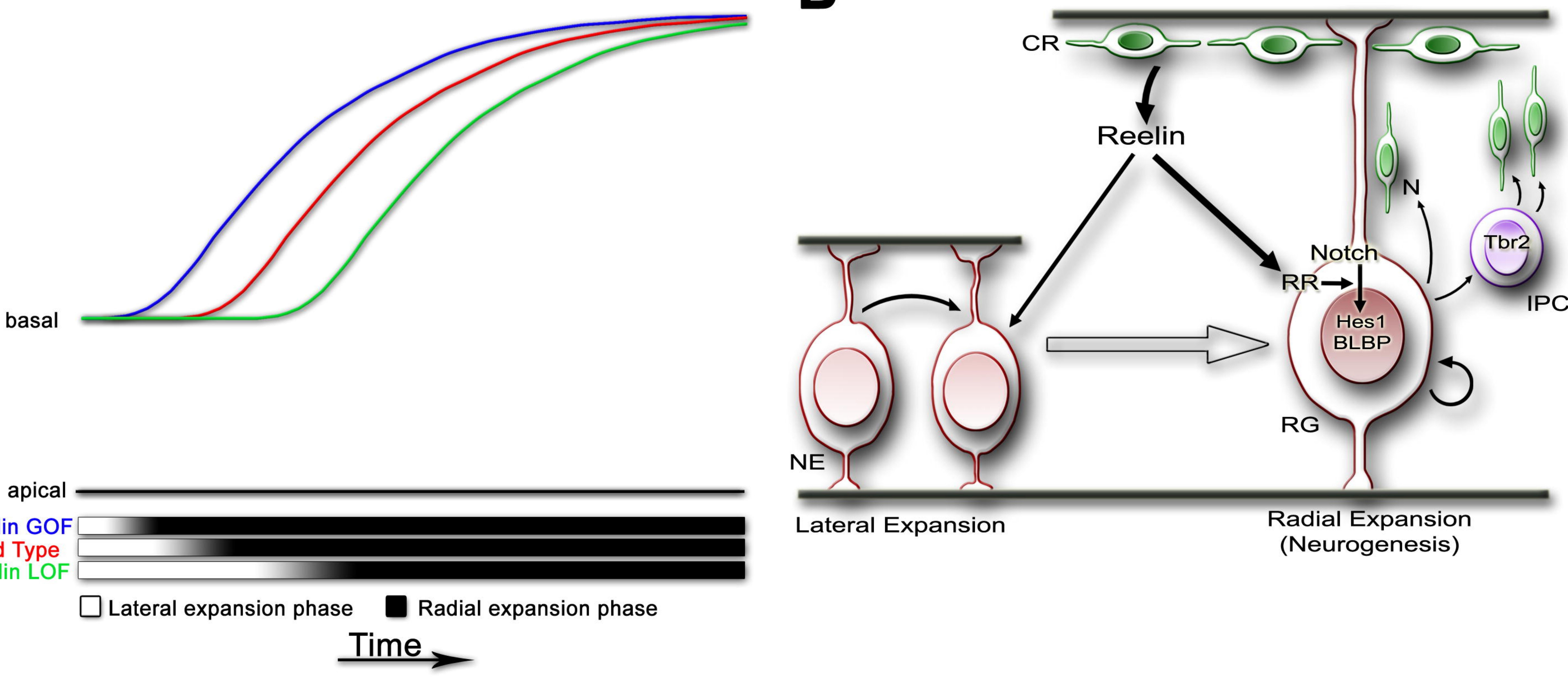

\section{FIGURE 7}

